\title{
ESSA PELE QUE HABITO - REFLEXÕES SOBRE TRANSEXUALIDADE, DISCRIMINAÇÃO E ABUSO ÀS GARANTIAS CONSTITUCIONAIS NO CONTEXTO DO DIREITO DO TRABALHO
}

\author{
Cláudia Roberta Leite Vieira*
}

\begin{abstract}
RESUMO
A exteriorização e afirmação da sexualidade podem representar processos extremamente dolorosos quando fogem dos padrões usuais aceitos para uma determinada sociedade. O propósito desse estudo é discutir a relação entre transexualidade, discriminação e dificuldade de inserção no mercado de trabalho formal. Para tanto, será dissertado acerca das designações terminológicas que envolvem o tema, bem como serão analisadas as questões médicas e jurídicas que regulam a matéria. Também são debatidos tópicos referentes aos mais recentes avanços na conquista de direitos pelas pessoas transexuais.
\end{abstract}

PALAVRAS CHAVE: Transexualidade, discriminação, mercado de trabalho formal.

\begin{abstract}
The externalization and sexuality affirmation may represent extremely painful processes when differs from the usual standards accepted for a specific society. The purpose of this study is to discuss the relationship between transsexuality, discrimination and difficulty in entering the formal labor market. For this intent, will be debated about the terminology assignments involving the theme as well as the medical and legal aspects on the subject. Also, will be discussed topics related to the latest and gradual achievements of rights for transexuals people.
\end{abstract}

KEY WORDS: Transsexuality, discrimination, formal labor market.

* Professora Associada (Doutora) do Departamento de Fisiologia e Patologia da Universidade Federal da Paraíba (UFPB). 


\section{INTRODUÇÃO}

Conforme assevera Sofia Vilela de Morais e Silva (2012), “o modo de exteriorização da sexualidade pode ser imensamente doloroso e complexo quando desarvora-se dos padrões ditos "normais" para uma determinada sociedade.

A expressão "transexualidade" refere-se a um desejo de viver e ser aceito enquanto pessoa do sexo oposto. Ess ânsia acompanha-se, em geral, de um sentimento de mal estar ou de inadaptação a seu próprio sexo anatômico e da vontade de submeter-se a uma intervenção cirúrgica e/ou a um tratamento hormonal a fim de tornar seu corpo tão conforme quanto possível ao sexo desejado (NEPOMUCENO, 2011).

As principais características da transexualidade são: a) a convicção de pertencer a outro sexo; b) aversão pelos próprios órgãos genitais; c) o interesse pela adequação dos genitais ao sexo almejado.

A pessoa transexual tem o firme anseio de adequar a genitália ao seu sexo psíquico, como forma de se libertar da contradição de ter o sexo biológico diferente da forma com a qual se autodetermina.

Diferente da homossexualidade, aduz Sofia Vilela de Morais e Silva (2012), que foi excluída do rol de transtornos mentais desde 1990 pela Organização Mundial da Saúde (OMS), a transexualidade, ainda hoje, é considerada uma doença, segundo a Classificação Internacional de Doenças da OMS em sua $10^{\mathrm{a}}$ versão (CID-10).

O grupo F-60 a F-69 (capítulo V) do CID-10 reúne os chamados Transtornos da Personalidade e do Comportamento do Adulto. O Transtorno de Identidade de Gênero está compreendido no item F64: Transtornos da Identidade de Gênero: F64.0 Transexualismo; F64.1 - Travestismo Bivalente; F64.2 - Transtorno de identidade sexual na infância (CORDEIRO, 2011). Segundo a autora:

O termo Travestismo bivalente - ou de duplo-papel - designa a vontade e insistência em usar vestimentas do sexo contrário durante um determinado período da vida, de modo a satisfazer a experiência temporária de pertencer ao sexo oposto, mas sem vontade de alteração sexual mais permanente ou de uma transformação 
cirúrgica. A mudança de vestimenta não se acompanha de excitação sexual. Trata-se de um transtorno de identidade de gênero no adulto ou adolescente, do tipo não transsexual (grifo da autora). Em gradações e intensidades diferentes, travestis e crossdressers encontram-se inseridos nessa categoria.

No mesmo diapasão, em acordo a autora supradita e com os ensinamentos de Bento Manoel de Jesús (2013) e Esalba Maria Carvalho Silveira (2006), o denominado Transtorno de identidade sexual na infância:

[...] manifesta-se no início da infância e sempre bem antes da puberdade, caracterizando-se por um persistente e intenso sofrimento em pertencer a um dado sexo, junto com um anseio de ser (ou insistência de que se é) do sexo oposto. Há uma preocupação excessiva com a roupa e as ocupações do sexo inverso e o repúdio ao próprio sexo. O diagnóstico requer uma profunda perturbação da identidade sexual. $\mathrm{O}$ esclarecimento do diagnóstico em crianças e adolescentes pode exigir um extenso período de monitoramento. Em meninos, a identificação com o gênero contrário se manifesta por um acentuada preocupação com atividades tradicionalmente femininas. Eles podem manifestar uma preferência por vestir-se com roupas de meninas ou mulheres, ou improvisar esses itens a partir de materiais disponíveis, quando os artigos genuínos não estão à sua disposição. Toalhas, aventais e lenços frequentemente são usados para representar cabelos longos ou saias. Eles, não raro, chegam a expressar uma aflição de serem meninas e declarar que, quando crescerem, serão mulheres. Pode haver, também, uma insistência em urinar sentados e em fingir que não possuem pênis, escondendo-o entre as pernas. Mais raramente, os meninos com Transtorno de identidade sexual na infância podem afirmar que têm aversão por seu pênis ou testículos, que gostariam de removê-los e que desejariam ter uma vagina. Já as meninas com esse distúrbio apresentam reações negativas intensas às expectativas ou tentativas dos pais de que se vistam com roupas femininas. Algumas podem recusar-se a comparecer à escola ou a eventos sociais em que essas roupas são exigidas. Elas podem afirmar a vontade de ter um pênis e que não desejam desenvolver seios ou menstruar. Chegam, por vezes, a declarar que, quando crescerem, serão um homem. Essas meninas, tipicamente, revelam acentuada identificação com o sexo contrário em brincadeiras, sonhos e fantasias. 
Cabe mencionar, nesse cenário, que, na opinião de Desirèe Monteiro Cordeiro (2011), todo transexual foi portador de Transtorno de identidade sexual na infância, mas nem toda criança que teve esse diagnóstico se desenvolverá transexual, a maioria, diz a autora, se identificará como homossexual.

No que se refere à temática da transexualidade, objetivo fulcral desse estudo, vale trazer à baila algumas reflexões acerca da denominação "identidade de gênero":

"Identidade de gênero" foi um termo pautado no ano de 1964 pelo pesquisador americano Robert Jesse Stoller para indicar o sexo com o qual a pessoa se identifica, isto é, a sensação interior, psíquica, de pertencer ao sexo masculino ou feminino, como informa Sofia Vilela de Morais e Silva (2012).

É relevante, pois, nessa questão, tecer considerações a respeito dos conceitos de sexo e de gênero:

Sexo, na concepção da autora supracitada, refere-se à clássica divisão biológica entre macho e fêmea, sendo uma caracterização pertinente à anatomia, à genética e à fisiologia do ser humano. Se a criança nasce com pênis, é um macho; se com vagina, é uma fêmea. Por vezes, os dois órgãos sexuais aparecem simultaneamente em um único indivíduo, gerando os chamados intersexos ou hermafroditas.

Miriam Pillar Grossi (1998) esclarece que o conceito de gênero tem seus primórdios em estudos realizados por pesquisadoras norte-americanas que passaram a usar a categoria "gender" para refereir-se às "origens exclusivamente sociais das identidades subjetivas de homens e mulheres". Para a autora, a ênfase colocada na "origem social das identidades subjetivas" não é gratuita. De fato, não existe uma determinação natural dos comportamentos de homens e de mulheres, apesar das inúmeras regras sociais calcadas numa suposta determinação biológica diferencial dos sexos.

Leciona a autora supradita:

O conceito de gênero não remete apenas a ideias, mas também a instituições, a estruturas, a práticas cotidianas e a rituais, ou seja, a tudo aquilo que constituem as relações sociais. A diferença sexual 
não é a causa originária a partir da qual a organização social poderia ter derivado; ela é mais uma estrutura social movediça que deve ser ela mesma analisada em seus diferentes contextos históricos.

Na mesma tônica, para Sofia Vilela de Morais e Silva (2012), o termo gênero transcende o aspecto biológico para inserir-se na questão sociológica, ou seja, é, basicamente, uma construção social. Desse modo, há o gênero feminino (papel social voltado às mulheres) e o masculino (papel social de homem).

Nessa matéria, são importantes as observações da autora acima referida:

Os transexuais são, na realidade, pessoas que possuem uma extrema aversão ao seu fenótipo porque desejam fortemente ter a aparência do gênero com o qual se identificam, chegando, inclusive, a casos extremos de automutilação e suicídio. É, de fato, uma desconexão entre os órgãos genitais e a percepção subjetiva do gênero: um homem no corpo de uma mulher, uma mulher em um corpo de homem".

Essa cisão entre corpo e mente leva os transexuais a não reconhecerem o seu corpo enquanto unidade que lhes presentifica a vida. A impossibilidade de se compreender habitando o próprio corpo os faz negá-lo e amordaçá-lo (BRUNS, SANTOS, 2006). A sensação é de uma alma aprisionada a um corpo estranho ${ }^{4}$, uma percepção extremamente dramática e desconcertante, como realça Esalba Maria Carvalho Silveira (2006). Tal sentimento, por óbvio, acaba por traduzir-se num intenso e persistente sofrimento psíquico.

Na mesma vereda, menciona Sofia Vilela de Morais e Silva:

Nesses casos, existe a recomendação médica da cirurgia de "redesignação sexual", um procedimento cirúrgico indicado para esse grupo de indivíduos. Contudo, houve intensa luta pela legalização desse tipo de cirurgia no Brasil. Essa batalha se intensificou no início da década de 1970, quando um grupo de médicos do Hospital das Clínicas da cidade de São Paulo, sensibilizados com a quantidade de pessoas que procuravam esse procedimento, pressionou o governo para a regulamentação de tal intervenção médica. 


\section{Continua a autora supradita:}

"Apesar da falta da legalização, já no ano de 1971, foi realizada a primeira cirurgia de conversão de sexo no Brasil. Ressalte-se que o médico responsável foi indiciado pelo crime de lesão corporal grave, além de ter respondido a um processo administrativo no Conselho Federal de Medicina. Embora tenha sido absolvido ao final da lide, foi considerado culpado em primeira instância, chegando a ter cassado o seu direito ao exercício regular da medicina. Essa situação de ilegalidade perdurou por um tempo demasiado longo, até que em 10 de setembro de 1997, o Conselho Federal de Medicina (CFM) editou a Resolução n. 1.482/97, a qual definiu o transexualismo como um transtorno de identidade de gênero, delimitando os procedimentos de seleção de pacientes e considerando éticas as cirurgias de redesignação sexual, quando realizadas em hospitaisescolas sem fins lucrativos. Por fim, o Ministério da Saúde, por meio da Portaria n.1.107, instituiu, em agosto de 2008, no âmbito do Sistema Único de Saúde (SUS), o "Processo Transexualizador" (que inclui o procedimento cirúrgico e outras terapias, como a hormonal e a psicológica), o qual deve ser realizado em serviços de referência devidamente habilitados. Esse foi um passo importante, tendo em vista que houve um reconhecimento institucional da necessidade de proteger todos os transexuais."

Dados recentes do Ministério da Saúde mostram que foram realizadas 603 cirurgias de redesignição sexual, já no ano de 2012, nos quatro hospitais públicos especializados na técnica. Nos centros médicos de São Paulo, Rio de Janeiro, Porto Alegre e Goiânia foram, em média, duas cirurgias diárias em 2012 (ARANDA, 2013).

Entretanto, mesmo após lograr uma vaga no SUS e realizar a cirurgia, a pessoa transexual ainda tem mais um desafio: conseguir a alteração no seu registro civil. Como não há norma legal expressa regulando a matéria, as pessoas que realizam a cirurgia de redesignação ingressam na justiça para pleitear a mudança do seu prenome na certidão de nascimento, passando a depender de uma sentença judicial favorável, como observa Sofia Vilela de Morais e Silva (2012). 


\section{DIFICULDADES NO ACESSO À FORMAÇÃO ESCOLAR, TÉCNICA E PROFISSIONALIZANTE}

Nessa questão, reflete Sofia Vilela de Morais e Silva (2012):

Ocorre que, após a cirurgia e até mesmo com a alteração do nome, as pessoas transexuais apresentam sérias dificuldades para se inserirem e serem aceitas no mercado de trabalho. Muitas, devido a esse fato, preferem o isolamento, abdicando de uma possível formação acadêmica e profissional, para evitar situações de constrangimento e humilhação. Em inúmeros casos, pelo intenso assédio físico e moral que sofrem, muitos transexuais não conseguem nem mesmo concluir o ensino fundamental.

Em adição, repise-se que, quando uma pessoa transexual chega à escola, ela já viveu muitos transtornos na esfera familiar e comunitária, apresentando uma base emocional fragilizada que a impede de enfrentar os processos de estigmatização e a discriminação que o próprio ambiente escolar exerce, com seus alunos, professores, funcionários e dirigentes, dada a desinformação a respeito do convívio com a diferença e suas singularidades. A intensidade da rejeição e do desrespeito acabam ocasionando o abandono dos estudos ou a expulsão da escola, conforme esclarece William Siqueira Peres (2009).

Para o autor supradito:

Aceitar a transexualidade, para muitas famílias, é um processo usualmente embaraçoso e, não fortuitamente, angustiante. $\mathrm{O}$ desconhecimento, os padrões morais e religiosos, bem como os papéis sociais culturamente determinados, entre outros fatores, levam parentes a não visualizarem nessa situação um momento protetivo, de união, acolhimento e solidariedade. Ao contrário, as famílias escolhem optar pela rejeição, abandono e exclusão.

Desse modo, muitas mulheres transexuais, por exemplo, não conseguem fugir de ocupações que, pelas suas características, implicam numa maior aceitação de sua condição, como as atividades desenvolvidas em salões de beleza (cabeleireiras e maquiadoras), em empresas do ramo do entretenimento, chegando, muitas vezes, aos casos de prostituição. 
Consoante refere William Siqueira Peres (2009), são frequentes os relatos de travestis e transexuais que reclamam por não terem conseguido estudar, sem possibilidade de acesso a uma faculdade e de exercer uma profissão que lhes garantisse a sobrevivência, tendo que recorrer à prostituição. Em suas falas, é frequente ouvir reclamações acerca da necessidade de se prostituir por não conseguirem empregos ou oportunidades de renda, sobrando-lhes apenas a "rua", como única possibilidade de ganhos financeiros. $\mathrm{O}$ autor relata que as pessoas transexuais são, usualmente, compelidas para os espaços de marginalidade, em consequência da violência estrutural a que são submetidas. As experiências da opressão, estigmatização e isolamento vividas por transexuais prejudicam a própria socialização desses indivíduos, restringindo seu universo existencial.

Vale mencionar, nesse tópico, que desde o ano de 2002, o Ministério do Trabalho e Emprego (MTE) traz em sua Classificação Brasileira de Ocupações (CBO), as categorias "travesti" e "transexual" como sinônimas de "profissional do sexo", ocupação identificada pelo código 5198-05 (MACDOWELL, 2009).

A intolerância, portanto, efetivamente rechaça a maioria das pessoas transexuais do respaldo educacional e do aperfeiçoamento técnico e profissionalizante.

\section{TRANSEXUALIDADE E O MERCADO DE TRABALHO FORMAL}

Ensina Sofia Vilela de Morais e Silva (2012) que, na área jurídica, a questão referente às diversas expressões da sexualidade é ainda pouco discutida e estudada, o que, em parte, justifica-se, já que um dos princípios basilares do direito é aquele que prima pela sua não interferência na esfera íntima das pessoas.

Contudo, é cediço que existe uma nítida relação entre transexualidade e discriminação no mercado de trabalho. Destarte, a relevância do direito laboral em se apropriar dessa temática.

O trabalho formal é praticamente inacessível às pessoas transexuais. Uma minoria tem formação superior ou qualificação profissional. Com poucas exceções, as únicas profissões exercidas são aquelas realizadas no ambiente doméstico e as ocupações 
relacionadas aos ramos da beleza e do entretenimento.

Para aquelas provenientes de famílias mais pobres, a prostituição se coloca como uma das poucas alternativas de geração de renda, se não a mais recorrente (FERREIRA, 2009).

Muitas mulheres transexuais que são rejeitadas pelas famílias e expulsas de casa, podem começar a trabalhar na prostituição já aos 12 anos. Para muitas transexuais, o ingresso na prostituição é apenas parte de um universo permeado pelo sentimento de exclusão dos espaços socialmente reconhecidos e valorizados (JIMENEZ, ADORNO, 2009). A maioria afirma ter buscado a prostituição por não conseguir emprego formal devido a preconceitos em razão de sua apresentação física (SOUSA, 2009).

Não causa surpresa o fato de que toda aquela manifestação da sexualidade que foge do esperado sofre segregação, inclusive no mercado de trabalho.

Nessa trilha, é válido mencionar que as pessoas transexuais costumam serem associadas à prostituição, violência e ilegalidade. Em razão de uma percepção subjetiva, preprojectada, são encaradas de modo negativo, o que as impede de serem aceitas no trabalho formal (SILVA, 2012).

É sabido que o mercado de trabalho possui uma estrutura segmentada pelo gênero, sendo definido pela dicotomia convencional homem/ mulher. Muitos valores subjetivos e avaliações preconcebidas estão embutidos nesta divisão. Desse modo, pessoas com uma ambiguidade de gênero poderiam despertar certa confusão e causar rejeição, a ponto de serem capazes de perturbar o desempenho da função, especialmete pelo fato de que, hodiernamente, muitas ocupações exercem vinculadas à apresentação e à imagem (CARVALHO, 2006).

As possibilidades de inserção no mercado de trabalho para as pessoas transexuais são mínimas e, mesmo nas situações em que mulheres transexuais executem atividades tidas como "femininas", elas não são, de fato, consideradas melheres e, pela ambiguidade, são alvo de preconceitos por parte do empregador (MOURA, LOPES, 2014) Aqui, a atribulação é duplamente penosa, pois se ainda existe adversidade enfrentada pelas mulheres para alcançar as mesmas condições salariais do homem, o desafio só aumenta para as transexuais. 
Desse modo, a falta de acesso ao mercado de trabalho formal por parte dos transexuais reflete os conceitos de hierarquia e dominação, estes baseados em relações sociais de classe, gênero, divisões étnicas e sexuais que reforçam e perpetuam as assimetrias de poder e produzem estigmas. Essa situação exige uma mobilização constante, uma luta incansável pela cidadania, que deve ser baseada na proteção aos direitos humanos e no respeito à diversidade sexual (CARVALHO, 2006).

É notório que grupos historicamente excluídos do mercado laboral passaram a ter maior acesso aos postos de trabalho, a exemplo das mulheres e dos portadores de necessidades especiais, o que ocorreu graças a um processo de reestruturação produtiva desencadeado a partir da década de 90, ampliando garantias trabalhistas. Entretanto, no que se refere ao grupo das pessoas transexuais, as dificuldades permanecem, conforme foi discutido ao longo desse trabalho.

\section{UMA LUZ NO FIM DO TÚNEL?}

Como lembra Evelyn Raquel Carvalho (2006), apesar de uma aparente invisibilidade, as pessoas transexuais estão inseridas no meio social, procurando ocupar seus espaços, ampliando suas possibilidades de inserção e de debate político sobre sua condição na sociedade.

No entrecho das recentes conquistas, é oportuno destacar que as pessoas transexuais obtiveram o direito de usar o nome social, aquele pelo qual preferem ser chamadas cotidianamente, em contraste com o nome oficialmente registrado, posto que não reflete sua identidade de gênero.

Para Patrícia Araújo (2011), entende-se por nome social aquele pelo qual travestis e transexuais se reconhecem, bem como são identificados por sua comunidade e em seu meio social.

A normatização a respeito do nome social espelha o respeito à dignidade das pessoas trans e demonstra, com o intuito de evitar constrangimentos, não somente respeito aos direitos fundamentais dessas pessoas, como também representa um avanço na inclusão social dos mesmos, uma vez que o nome é elemento diferenciador que individualiza e identifica a pessoa. 


\section{ALGUMAS CONSIDERAÇÕES FINAIS}

Por todo o exposto, é certeza hialina que a transexualidade está longe de ser uma escolha. Na verdade, quem escolheria passar por tal sofrimento: rejeitar seu próprio corpo, ser excluído e discriminado pela família, pelos amigos, pela comunidade e, afinal, por toda a sociedade? As pessoas transexuais enfrentam toda espécie de discriminação e humilhação que, muitas vezes, inicia-se ainda na infância, quando começam a serem vistas como "diferentes".

Em um post de 2013, o Jornalista Diego Cruz, fazia a seguinte meditação: "Quem se lembra de ter convivido com, no mínimo, uma pessoa transexual, seja na Universidade, no local de trabalho, no banco ou mesmo numa padaria, realizando atividades cotidianas?"

Basta, pois, uma simples reflexão para entender o quão os transexuais continuam excluídos da sociedade. É triste perceber que a esse grupo de pessoas estão sendo explicitamente negados os direitos fundamentais, de assento constitucional, que são garantidos a qualquer cidadão, a exemplo do acesso ao trabalho digno.

Infelizmente, na seara do acesso ao Mercado de trabalho formal, é desolador e paradoxal o cenário que ainda se descortina:

A despeito dos avanços recentes nas iniciativas governamentais, o que se observa é que nunca se teve tanto e o que existe é praticamente nada (MELLO; BRITO; MAROJA, 2012).

Portanto, faz-se urgente, além de imperioso, rever as políticas públicas que garantam o acesso dos transexuais ao Mercado de trabalho formal, cumprindo o mais relevante preceito da nossa Constituição, aquele que permeia toda a Magna Carta: o princípio da dignidade da pessoa humana.

Os homens e mulheres transexuais, não poucas vezes, sentemse presos dentro do seu próprio corpo. Uma prisão especialmente dolorosa, feita de pele, músculos, ossos e sangue.

Essa clausura, contudo, é incapaz de calar um irrefutável desejo: o anseio de resgatar a existência digna que a sociedade, injusta e covardemente, negou a esses indivíduos.

Por fim, é oportuna, no contexto, uma ponderação na esteira do que teoriza Maria Alves de Toledo Bruns e Claudiene Santos 
(2006): "compreender os diferentes modos de se expressar no mundo é se permitir entender a multiplicidade e a fluidez das identidades, papéis e representações de gênero"

\section{REFERÊNCIAS}

1. ARANDA, Fernanda. iG São Paulo. São Paulo, março de 2013. Disponível em: http://saude.ig.com.br/minhasaude/2013-03-11/brasilrealiza-duas-cirurgias-de-mudanca-de-sexo-por-dia.html. Acesso em 17/10/2013.

2. ARAÚJO, Patrícia. Revista Consultor Jurídico. Março de 2011. Disponível em http://www.conjur.com.br/2011-mar-21/travestistransexuais-nao-podem-adotar-nomes-civis-existentes. Acesso em 21/07/2015.

3. BRUNS, Maria Alves de Toledo. SANTOS, Claudiene. Diversidades sexuais, corpos e desejos em transformação. Revista da Sociedade de Psicologia do Triângulo Mineiro, Uberlândia, v. 10, n. 2, p. 105-108, jul/dez 2006

4. CARVALHO, Evelyn Raquel. UFSC, Florianópolis, Santa Catarina, agosto de 2006. Disponível em http://www.fazendogenero.ufsc.br/7/st_16.html. Acesso21/10/2013.

5. CORDEIRO, Desirèe Monteiro. Transtorno de identidade sexual em adultos. Dissertação (Mestrado em Ciências - Programa de Psiquiatria) Faculdade de Medicina, Universidade de São Paulo, São Paulo, 2011.

6. CRUZ, Diego. Portal do Partido Socialista dos Trabalhadores Unificado (PSTU), 19/09/2013. Disponível em: http://www.pstu.org.br/somos-todxsgabriela-monelli-pelo-fim-da-transfobia. Acesso em 16/02/2017.

7. FERREIRA, Rubens da Silva. A informação social no corpo travesti (Belém, Pará): uma análise sob a perspectiva de Erving Goffman. Ci. Inf., Brasília , v. 38, n. 2, p. 35-45, Agos. 2009.

8. GROSSI, Miriam Pillar. Identidade de gênero e sexualidade. Antropologia em Primeira Mão - Revista do Programa de Pós-Graduação em Antropologia Social/UFSC, Florianópolis, n. 24,1998.

9. JESÚS, Bento Manoel de. Campanha para a despatologização da transexualidade no Brasil: seu discursos e suas dinâmicas. Dissertação (Mestrado em Sociologia) - Programa de Pós-Graduação em Sociologia, Universidade Federal de Goiás, Goiânia, 2013. 
10. JIMENEZ, Luciene; ADORNO, Rubens, C. F. O sexo sem lei, o poder sem rei: sexualidade, gênero e identidade no cotidiano travesti. Cad. Pagu, Campinas , n. 33, p. 343-367, Dez. 2009.

11. MACDOWELL, Pedro de Lemos. Geografia do gênero: do (não) lugar de travestis e outros abjetos na cidade. Trabalho apresentado no XVI Encontro Nacional de Estudos Populacionais, realizado em Caxambu, MG. Brasil. 29 de setembro a 03 de outubro de 2008. Disponível em: http://www.abep.nepo.unicamp.br/encontro2008/docsPDF/ABEP2008_146 7.pdf. Acesso em 13 de setembro de 2013.

12. MALUF, Vladimir. Excluídas do mercado de trabalho, travestis encontram sustento e aceitação na prostituição - Comportamento - UOL Mulher 27/09/13 14:40. Disponível em: http://mulher.uol.com.br/comportamento/noticias/redacao/2011/12/0...alhotravestis-encontram-sustento-e-aceitacao-na-prostituicao.htm. Acesso em 25/09/2013.

13. MELlO, Luiz; BRITO, Walderes; MAROJA, Daniela. Políticas públicas para a população LGBT no Brasil: notas sobre alcances e possibilidades. Cad. Pagu, Campinas, n. 39, Dez. 2012. Disponível em: http://www.scielo.br/scielo.php?script=sci arttext\&pid=S01048333201200020001. Acesso em 29 Out. 2013.

14. MOURA, Renan Gomes de., LOPES, Paloma de Lavor. O preconceito e a discriminação de transgêneros no processo de recrutamento e seleção de pessoal: uma revisão bibliográfica. Resende, outubro de 2014. Disponível em: http://www.aedb.br/seget/arquivos/artigos14/36520376.pdf. Acesso em 30/07/2015.

15. NEPOMUCENO, Cleide Aparecida. Transexualidade e o direito a ser feliz como condição de uma vida digna. Âmbito Jurídico, Rio Grande, v. XIV, n. 90, jul 2011. Disponível em: <http://www.ambito juridico.com.br/site/index.php?n_link=revista_artigos_leitura\&artigo_id=98 96>. Acesso em 29 de jul. 2015.

16. PERES, Wiliam Siqueira. Cenas de exclusões anunciadas: travestis, transexuais, transgêneros e a escola brasileira. Diversidade sexual na Educação: problematizações sobre a homofobia nas escolas. Brasília: Ministério da Educação, Secretaria de Educação Continuada, Alfabetização e Diversidade, UNESCO, p. 235-263, 2009

17. SILVA, Sofia Vilela de Moraes e. Transexualidade e discriminação no mercado de trabalho. Jus Navigandi, Teresina, ano 17, n. 3301, 15jul. 2012. Disponível em: 〈http://jus.com.br/artigos/22199>. Acesso em: 10 set. 2013.

18. SILVEIRA, Esalba Maria Carvalho. De tudo fica um pouco: a 
construção social da identidade do transexual. Tese (Doutorado em Serviço Social) - Faculdade de Serviço Social, Programa de Pós-Graduação em Serviço Social, Pontifícia Universidade Católica do Rio Grande do Sul, Porto Alegre, 2006.

19. SOUSA, Dayanne. Ensino profissional pode chegar a travestis. Brasília, junho de 2009.2 Disponível http://www.pnud.org.br/Noticia.aspx?id=2136. Acesso em 25/09/2013. 